\title{
Comparison of Depression and Quality of Life Between Patients on Hemodialysis and Their Spouses
}

\author{
Nayereh Baghcheghi ${ }^{1}$, Hamid Reza Koohestani2 ${ }^{*}$
}

1. Assistant Professor, School of Nursing and Midwifery, Saveh University of Medical Sciences, Saveh, Iran

2. Assistant Professor, School of Nursing and Midwifery, Saveh University of Medical Sciences, Saveh, Iran

\begin{tabular}{|c|c|}
\hline Article Info & ABSTRACT \\
\hline $\begin{array}{l}\text { Received: 2019/07/31; } \\
\text { Accepted: 2019/09/07; } \\
\text { Published Online: } 2020 / 06 / 24\end{array}$ & $\begin{array}{l}\text { Introduction: Patients on hemodialysis and their spouses experience various } \\
\text { stresses during illness and dialysis treatment. The aim of this study was to compare } \\
\text { depression and quality of life between patients on hemodialysis and their spouses. }\end{array}$ \\
\hline do 10.30699 /ajnmc.28.2.136 & $\begin{array}{l}\text { Methods: An analytical and cross-sectional study was performed using the } \\
\text { WHOQOL-Questionnaire tool and Beck Depression Inventory-II to assess the } \\
\text { quality of life and the depression, respectively. A total of } 172 \text { participants ( } 86 \text { patients } \\
\text { undergoing hemodialysis and } 86 \text { of their spouses) from two hospitals participated in } \\
\text { the study. }\end{array}$ \\
\hline $\begin{array}{l}\text { Use your device to scan } \\
\text { and read the article online }\end{array}$ & $\begin{array}{l}\text { Results: In total, } 89.54 \% \text { and } 91.87 \% \text { of patients on hemodialysis and their } \\
\text { spouses had depression at varying levels (mild to severe), respectively. The mean } \\
\text { score of depression in the spouse group was significantly higher than the patients } \\
\text { score }(P<0.05) \text {. Also, the spouses' score in psychological health domain of the } \\
\text { quality of life was significantly lower than the patients' score }(P<0.05) \text {. }\end{array}$ \\
\hline $\begin{array}{ll}0 \\
0\end{array}$ & $\begin{array}{l}\text { Conclusion: Depression is highly prevalent among patients on hemodialysis and } \\
\text { their spouses. Spouses had higher rates of depression and lower quality of life in } \\
\text { psychological health domain than patients. Therefore, it is suggested that, like patients, } \\
\text { the depression and quality of life of their spouses should be assessed periodically and, } \\
\text { if necessary, supportive measures should be taken. }\end{array}$ \\
\hline
\end{tabular}

Keywords: Depression, Quality of life, Hemodialysis, Spouses, Family caregivers

Corresponding Information:

Hamid Reza Koohestani, Assistant Professor, School of Nursing and Midwifery, Saveh University of Medical Sciences, Saveh, Iran. Email: Koohestani709@gmail.com

Copyright $($ C 2020, This is an original open-access article distributed under the terms of the Creative Commons Attribution-noncommercial 4.0 International License which permits copy and redistribution of the material just in noncommercial usages with proper citation.

\section{How to Cite This Article:}

Baghcheghi N, Koohestani H R. Comparison of depression and quality of life between patients on hemodialysis and their spouses. Avicenna J Nurs Midwifery care. 2020; 28 (2):136-143 


\section{مقايسُٔ ميزان افسردگى و كيفيت زندكى بيماران تحت همودياليز و همسران آنها

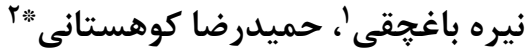

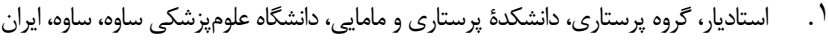

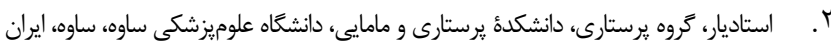

\begin{tabular}{|c|c|}
\hline جكيده & اطلاعات مقاله \\
\hline 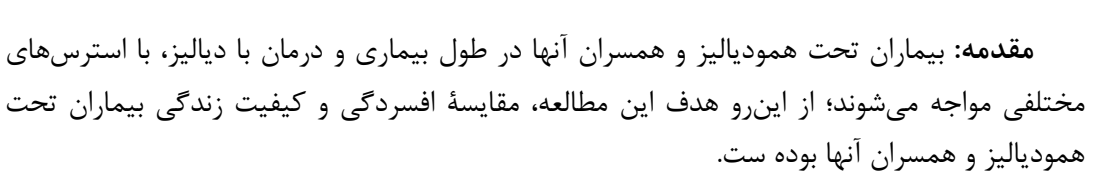 & 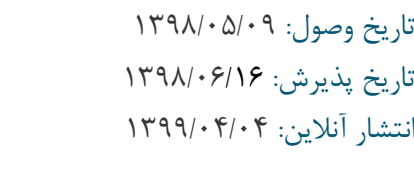 \\
\hline 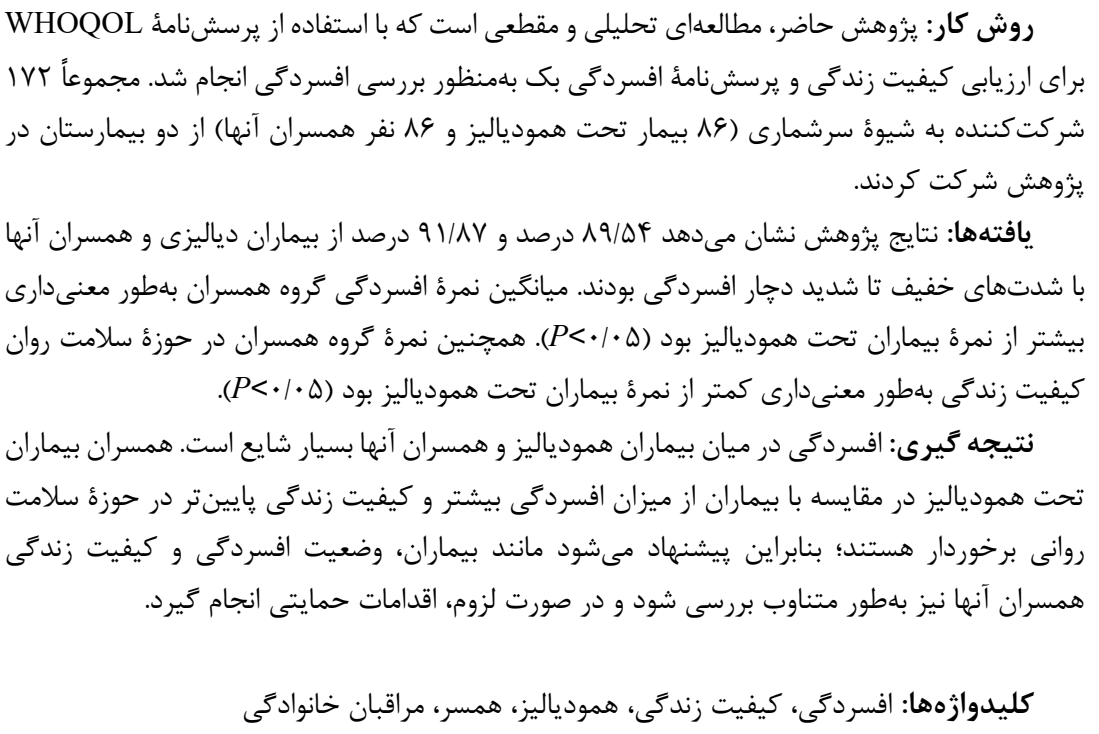 & 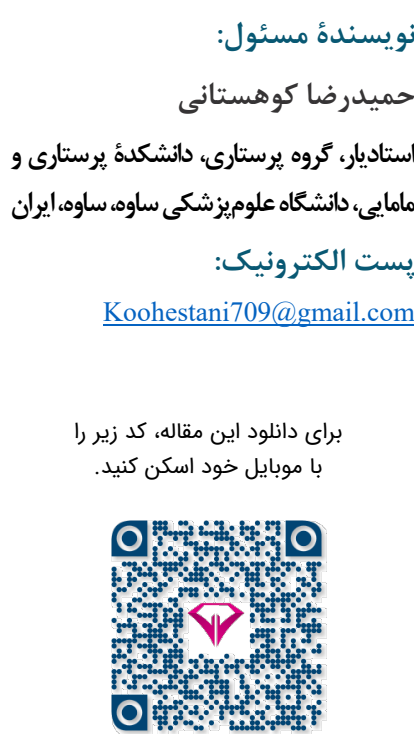 \\
\hline
\end{tabular}

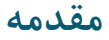

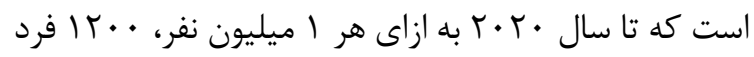
به نارسايى مزمن كليوى مبتلا شوند [ه].

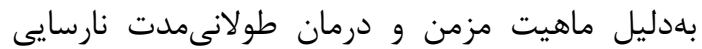
مزمن ييشروندة كليه، بروز تغييرات در عملكرد خانواده

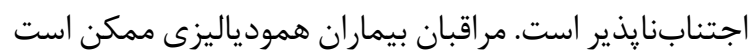
بار سنگينى بر دوش خود احساس كنند؛ زيرا آنها مجبور هستند نقش مهرى در حمايت از اين بيماران ايفا كنند.

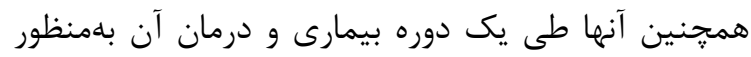

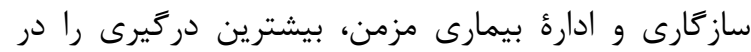
مراقبت از بيمار و كمك به آنان دارند و از آنها به به بيماران

ينهان تعبير مىشود [c].
نارسايى مزمن كليه مشكل جهانى سلامت محسوب مىشود كه با ناخوشى و مرگومير بالايى همراه است [1]. طبق كزارش سازمانى جهانى سلامت، بيمارىهاى كليه و

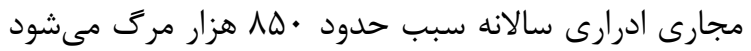

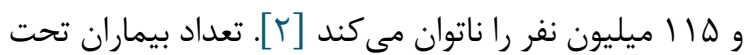

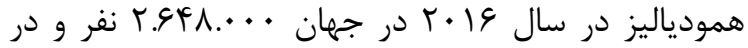

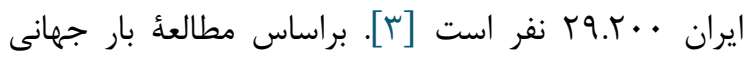

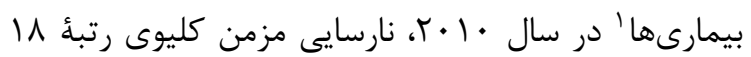
علت مرگومير در سراسر جهان را دارد؛ درحالى كه در سال 199.

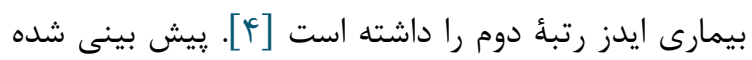

1. Global Burden of Disease 
ارزشمند است. مطالعات نشان مىدهد وضعيت روانى ساير

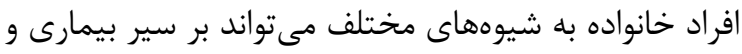

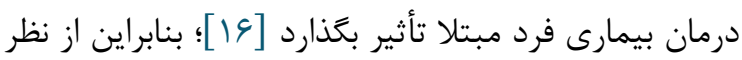

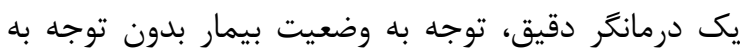

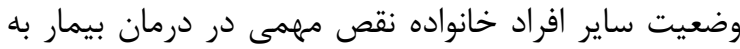

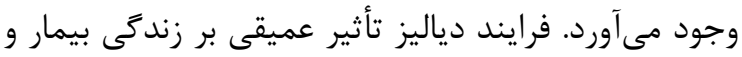

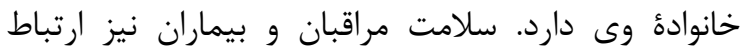
تنكاتنكى با هم دارد. با اين حال بيشتر مطالعات به بيمار باردان

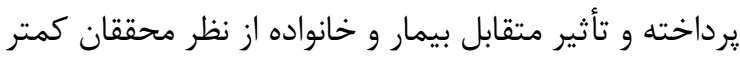

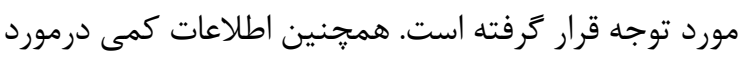

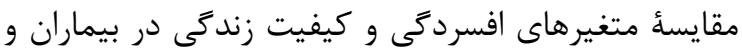

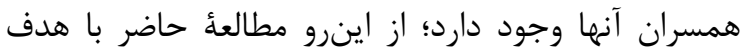

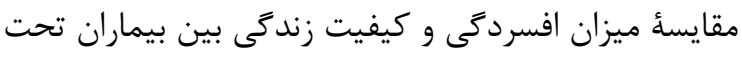
همودياليز و همسران آنها انجام شده است.

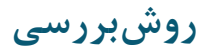

يزوهش حاضر يك مطالعه تحليلى-مقطعى است كه از

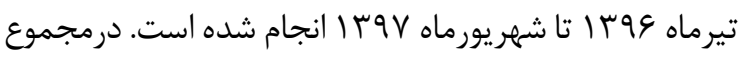
IVT همسران آنها) از دو بيمارستان وابسته به دانشكدئ علوميزشكى ساوه وارد يزوهش شدند. دو بيمارستان تحت يوشش دانشكدة علوميزشكى ساوه هستند. همجنين در اين مطالعه كل جامعأ يزوهش بلهصورت سرشمارى وارد مطالعه

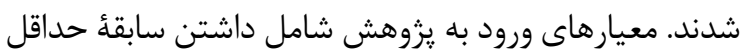

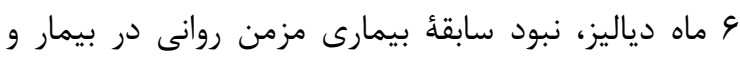

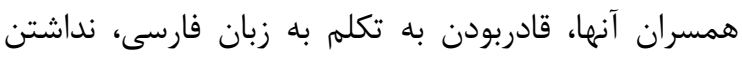

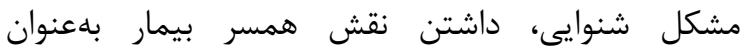

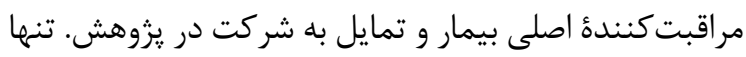

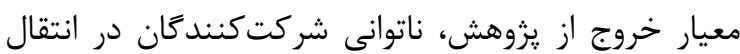
اطلاعات به يزوهشكر بود. ابزار استفادهشه در اين مطالعه بران يرسشنامهاى سهقسمتى بود كه قسمت اول شامل اطلاعات

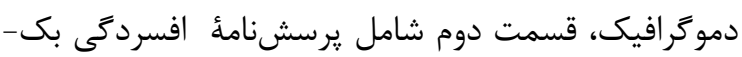
r و قسمت سوم شامل يرسشنامئ كيفيت زندگى سازمان بهداشت جهانى -فرم كوتاه بو بود.

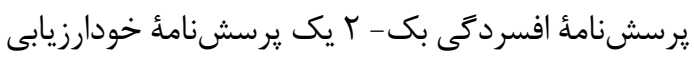

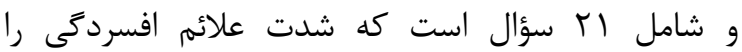
مى سنجد. هر ماده (نشانهٔ بيمارى) براساس شدت آن به جهار
براساس مطالعات، تجربئ روانشناختى مراقبان شامل افسردگى، اضطراب، عصبانيت، ترس، نكرانى و احساس كناه است. همجنين بهدنبال مراقبت از بيمار، سلامت جسمانى، رسيدگى به فعاليتهاى روزمره و شرايط اقتصادى مراقبان

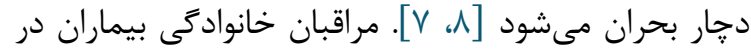

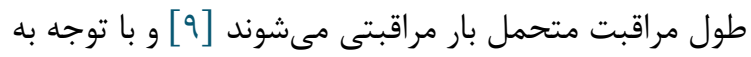
تأثير منفى بيمارى بر كيفيت زندكى مراقبان، احتمال ابتلاى آنان به بيمارىهاى جسمى و روانى افزايش مى يابد [ · [1]

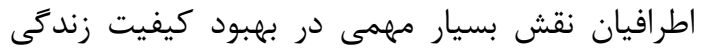

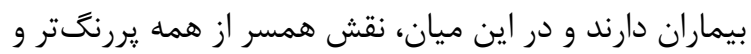

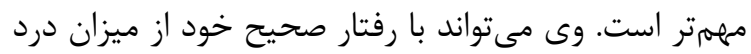
و رنج بيمار بكاهد و فرايند بهبود را تسريع بخشد. بيمارى

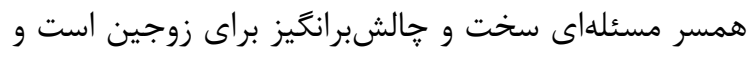
ابتلاى همسر به نارسايى مزمن كليه بر عواطف زوجين تأثير زئير

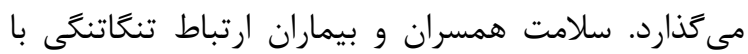
يكديكر دارد و مراقبان مى توانند در سلامتى و بهببود شرايط

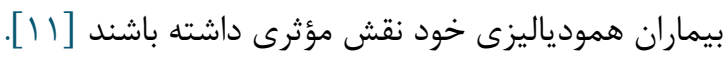
ميزان افسردىى در بيماران تحت همودياليز فراوان است

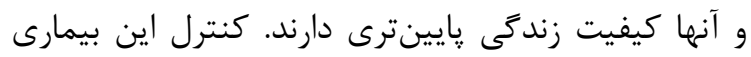
بسيار سخت است و بايد فرد با ابعاد متعددى از بيمارىى دارئ

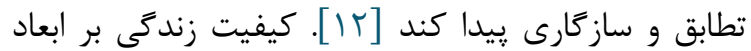

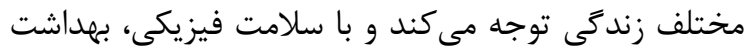
روانى، روابط روبهِيشرفت با مردم، شركت در فعاليتهاى اجتماعى و داشتن حس خودشكوفايى شناخته ميىشود. كيفيت زندگى بهعنوان يك اولويت مههم بهداشتى است كه

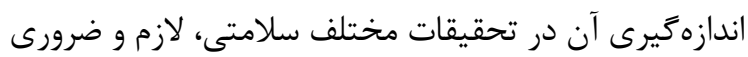

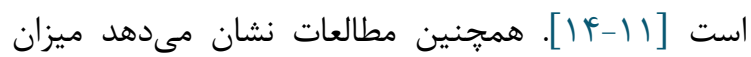
افسردگى در مراقبان در كشورهاى توسعهيافته بين سج تان

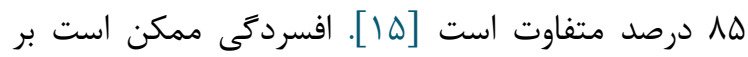

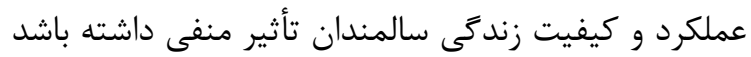
[19]. اين بيمارى از اساسىترين علل ايجاد ناتوانى در جهان

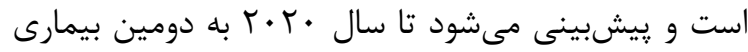

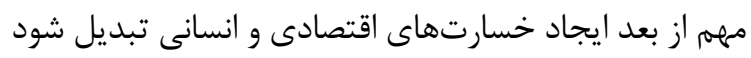

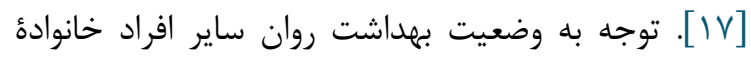
بيماران نهتنها از جهت كمك به درمان و ييشخيرى از عود

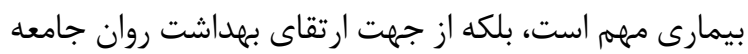

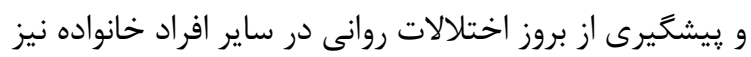

\footnotetext{
2. WHOQOL- BREIF
} 
همسانى درونى يرسشنامه مذكور بود. تجزيه و تحليل

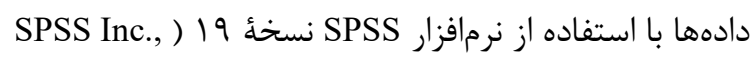
t انجام شد و از آزمونهاى آمارى (Chicago, Ill., USA مستقل و همجنين كاى اسكوير مستقل استفاده شد. بهمنظور رعايت ملاحظات اخلاقى محقق يس از بيان اهداف

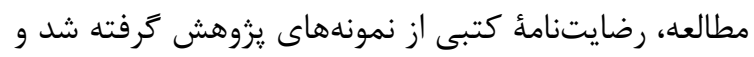

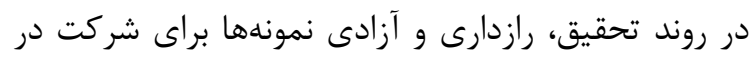

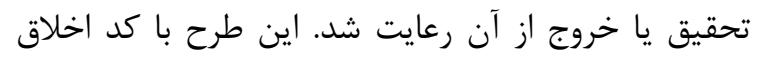

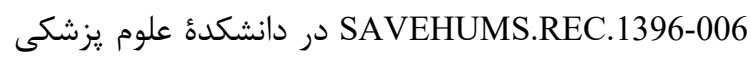
ساوه به تصويب رسيده است.

\section{بافته ها}

مجموعاً IVT نفر (1) بيمار تحت همودياليز و

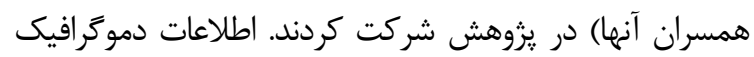
شركت كنندگان به اين شرح است: از عم بيمار شركت كننده در در

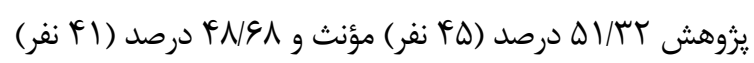

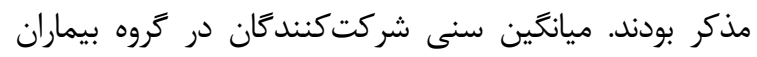

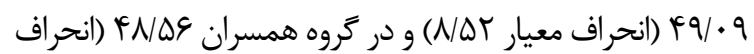

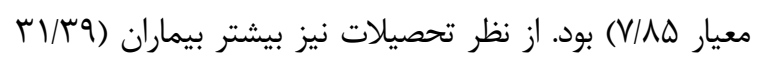

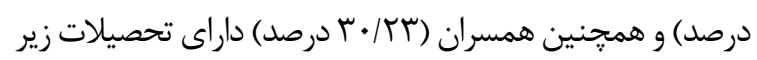

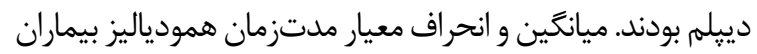

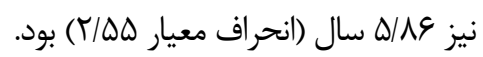

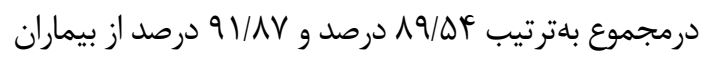
دياليزى و همسران آنها با شدتهاى متفاوت (خفيف تا شديد)

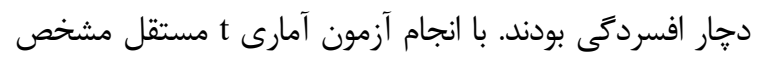

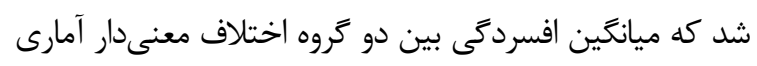

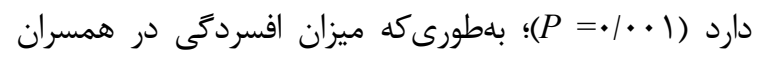

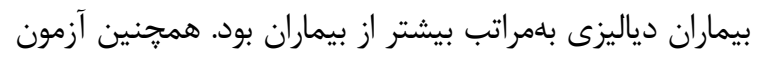

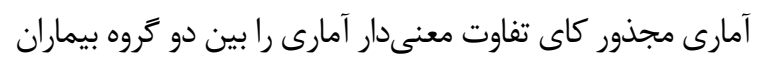

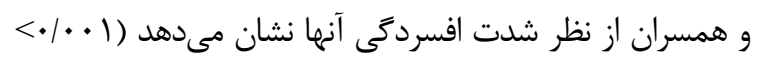
P

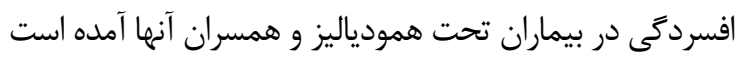

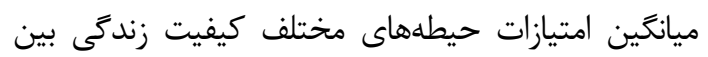

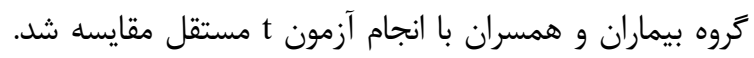

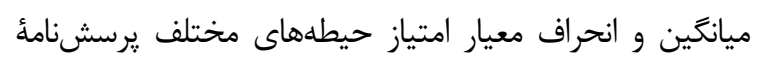

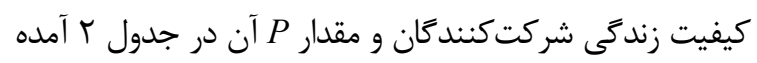

درجه تقسيم شده و از صفر تا س نمره مى گيرد. نمرهٔ صفر نشاندهنده يايينترين ميزان و نمره ب بيان كننده بالاترين

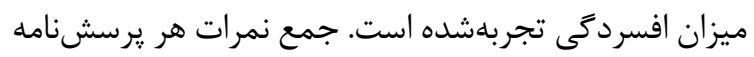

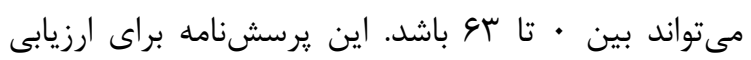

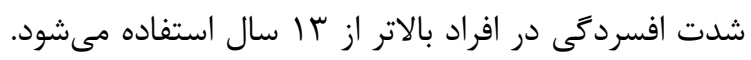

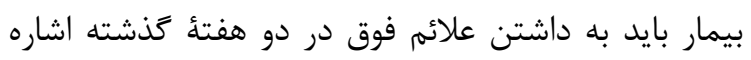

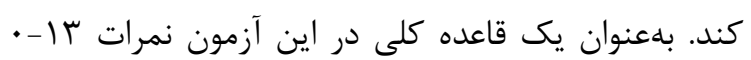

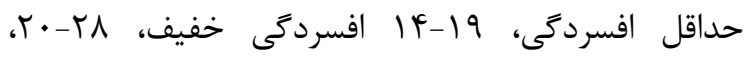

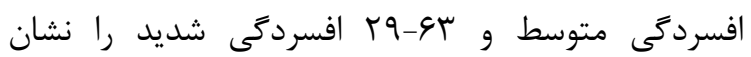

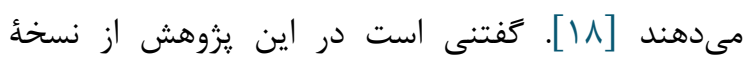
ترجمهشده ابزار توسط Ghassemzadeh و همكاران استفاده شد [19]. در يزوهش حاضر جهت إز تعيطين روايى علمى، از روش روايى محتوا و شاخص اعتبار محتوا استفاده شد.

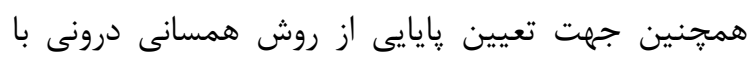

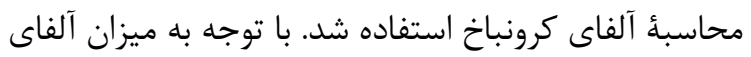

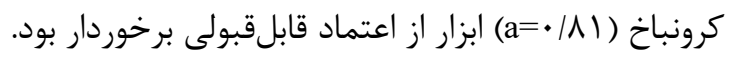

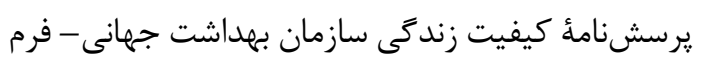
كوتاه كيفيت زندكى را بلهورت كلى و عمومى مى سنسجد.

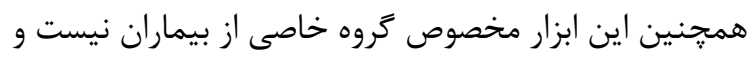

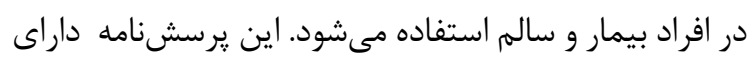
جهار حيطة سلامت جسمانى (V سؤال)، سلامت روانى (

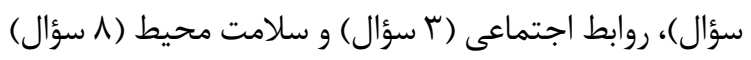
در TY سؤال است. همجنين دو سؤال ديخر نيز دارد كه به

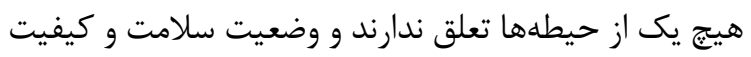

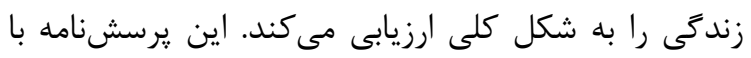
طيف ليكرت ينجدرجهاى است. براى تفسير و مقايسُٔ بهتر حيطهها نمرات خام به نمرات استانداردشده تبديل مى شئند

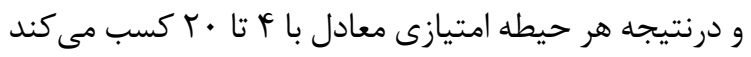

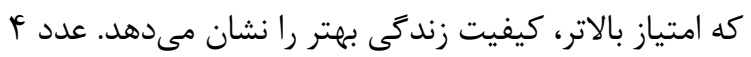

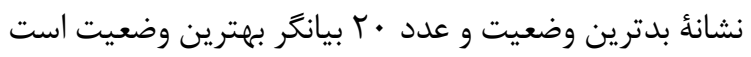

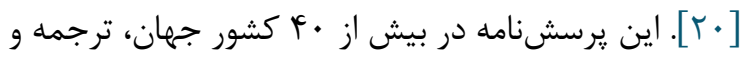

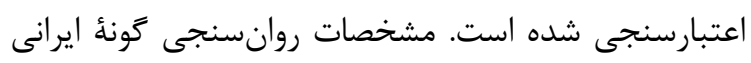

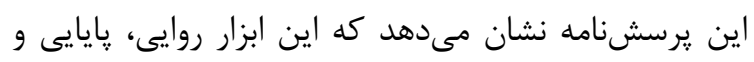

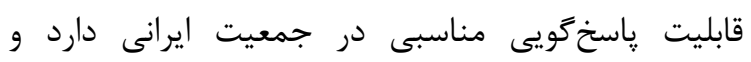

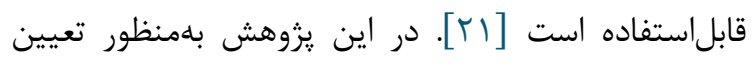

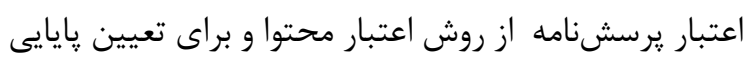

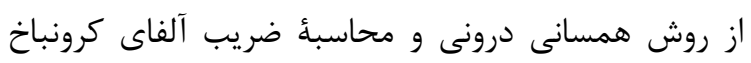
استفاده شد. محاسبة ضريب آلفاى كرونباخ (191/) مؤيد 
lf مقايسٔ ميزان افسردىى و كيفيت زندگى بيماران تحت همودياليز و همسران آنها

جدول ا. مقايسٔ فراوانى، ميانكَين و انحراف معيار ميزان افسردَى در بيماران تحت همودياليز و همسران آنها

\begin{tabular}{|c|c|c|c|c|c|}
\hline \multirow[t]{6}{*}{$\boldsymbol{P}$} & \multicolumn{2}{|c|}{ همسران } & \multicolumn{2}{|c|}{ بيماران } & \multirow{2}{*}{ افسردكى } \\
\hline & درصد & تعداد & درصد & تعداد & \\
\hline & N/T & v & 1.149 & 9 & بدون افسردگى (rا -••) \\
\hline & MY/M & r. & 4.199 & ra & خفيف (19-19) \\
\hline & $r V / r$ & rt & rF/M & $r \cdot$ & متوسط (r^-•r) \\
\hline & $19 / v 9$ & IV & $1 \% / 90$ & ir & شديد (ץ-99) \\
\hline$(P=\cdot / \cdot \cdot 1)$ & & & & & ميانَين و انحراف معيار نمره \\
\hline
\end{tabular}

جدول r. مقايسٔ ميانكَين امتيازات حيطههاى كيفيت زندگى بيماران تحت همودياليز و همسران آنها

\begin{tabular}{|c|c|c|c|c|}
\hline Pقدار P P P & 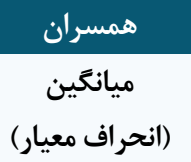 & 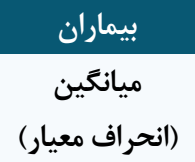 & محدوده امتياز & حيطه زاى كيفيت \\
\hline $.1 \cdot r$ & $1 T / \wedge 9(T / \cdot r)$ & $1 \cdot / T(T / 1)$ & $r \cdot-r$ & سلامت جسمانى \\
\hline.$\cdot .1$ & $N \wedge \mathcal{N}(\Psi / \cdot \Delta)$ & $1 \cdot / A V(T / \Delta I)$ & $r \cdot-r$ & سلامت روانى \\
\hline$\cdot / \mathrm{VA}$ & $\mid r / V T\left(T / T^{\mathcal{C}}\right)$ & $1 T / 99(T / V)$ & $r \cdot-r$ & روابط اجتماعى \\
\hline .94 & $\mid r / \Delta q(T / \mid F)$ & $\mid \Gamma / 9 \wedge(\Gamma / 99)$ & $r \cdot-r$ & سلامت محيط \\
\hline$\cdot / \Lambda$ & $T / V \mid(\cdot \mid \Delta \Delta)$ & $T / q T(\cdot / 4 q)$ & $\Delta-1$ & كيفيت زندكى كلى \\
\hline$\cdot / \cdot r$ & r/AV $(\cdot \mid G Y)$ & $1 / V V(\cdot / \Delta \varphi)$ & $\Delta-1$ & رضايت از سلامت \\
\hline
\end{tabular}

ندارند، بلكه در مقايسه با همسر بيمار خود ميزان افسردگى

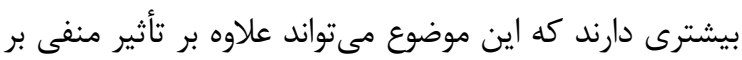

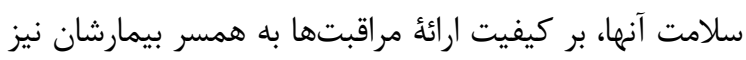
تأثير كذار است.

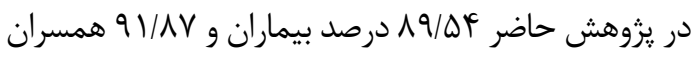

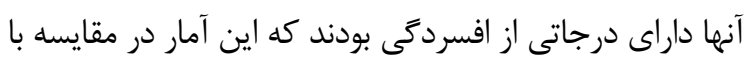

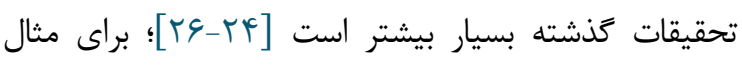
براساس تحقيق Hawamdeh و همكاران، 9N/9 درصد از بيماران و سه درصد مراقبان بيماران مبتلا به نارسايى كليه دجار

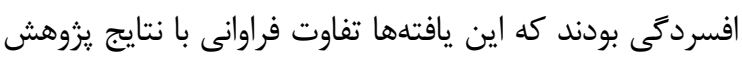

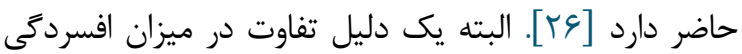

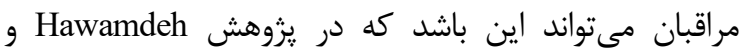

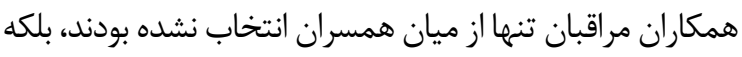

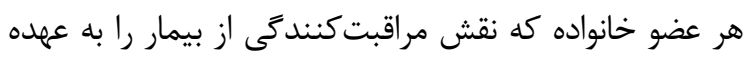
داشت، وارد يُزوهش شده بود.

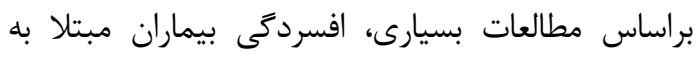

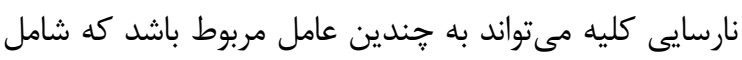
واكنش به تشخيص بيمارى و نياز به درمان مادامالعمر و اثر اين
مقايسٔ ميانكين دو كروه اختلاف معنىدار آمارى را در حيطههاى سلامت جسمانى، سلامت روانى و رضايت از

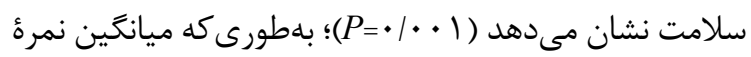
سلامت روانى در همسران بيماران دياليزى كمتر از تروه

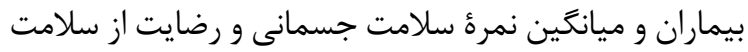

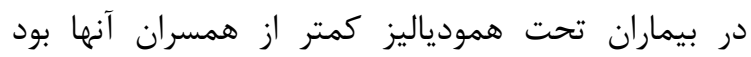
. $(P<\cdot / \cdot \Delta)$

\section{بحث}

نتايج اين يزوهش نشان مىدهد علاوه بر اينكه عوارض

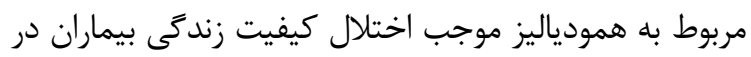
حوزهاى جسمى، روانى، اجتماعى و محيطى مىشودي، همسران

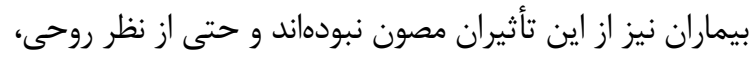
روانى و افسردحى نسبت به بيمار خود در وضعيت بدترى نيز

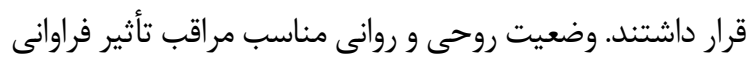
بر سلامت و بازگشت به سلامتى بيمار مزمن خواهد

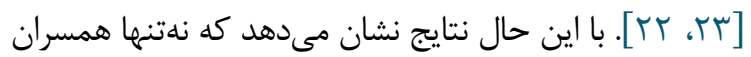

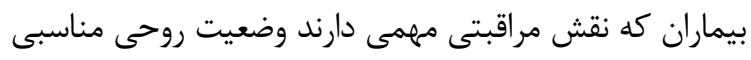


نتايج اين تحقيق با شناخت و مقايسٔ ابعاد كيفيت زندكى

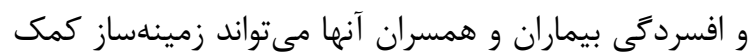

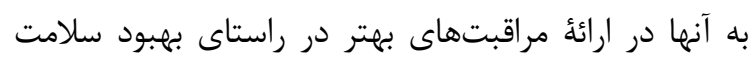

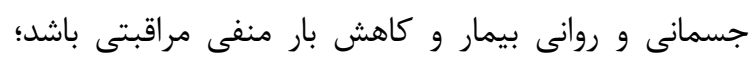

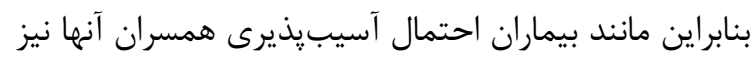
مطرح است و حتى اين گروه در بعضى از حوزهها از جمله

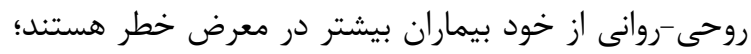

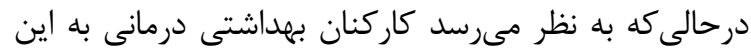

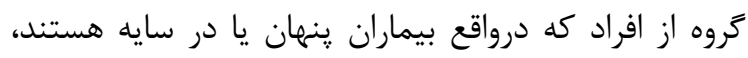
آنطور كه بايد توجه نمى كنند. بلهوركلى نتايج نشان مىدهد كه افسردگى در ميان بيماران همودياليز و همسران آنها بسيار شايع است. همسران

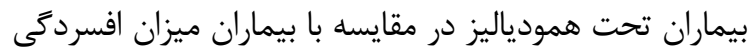
بيشتر و كيفيت زندگى بايينترى در حوزه سلامت روانى دارند. با توجه به نتايج يزوهش حاضر مىتوان كفت همسران بيماران

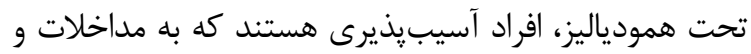

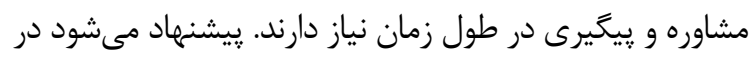
برنامهريزىهاى سيستم درمانى به نقش همسر بيماران در

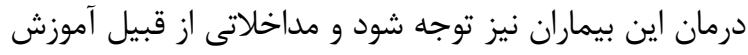

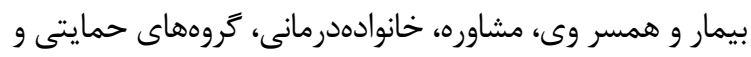
خدمات ارجاعى براى كاهش فشارهاى روحى و روانى و بهببود

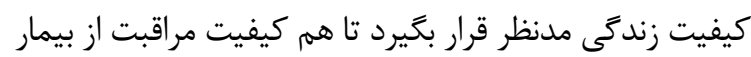

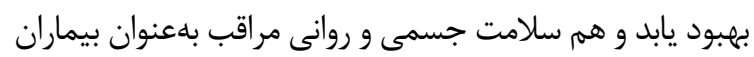

$$
\text { ينهان تضمين شود. }
$$

\section{نتيجه كيرى}

درمجموع نتايج تحقيق حاكى از احتمال شيوع بالاى

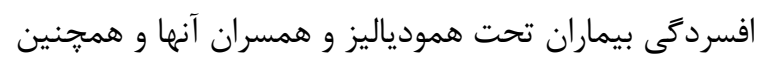

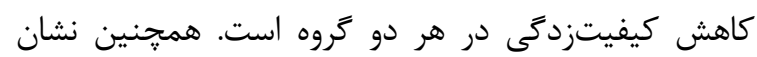
مىدهد كه همسران بيماران تحت همودياليز در مقايسه با ديان

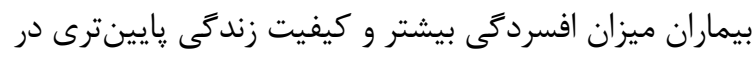
حوزه سلامت روانى دارند. همسران بيماران تحت همودياليز،

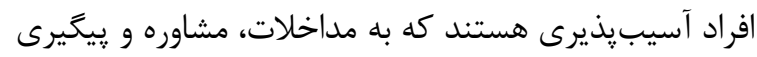
در طول زمان نياز دارند و يرستاران در اين حوزه مىتواندئن

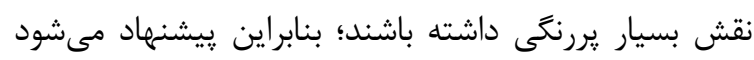

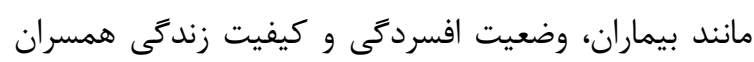
آنها نيز بهطور متناوب بررسى شود و بر مبناى نتايج اقدامات

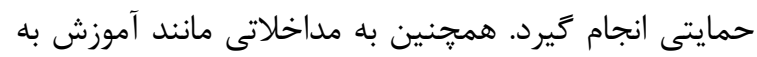

درمانهاى درازمدت، مانند اختلال كيفيت زندگى، از دست

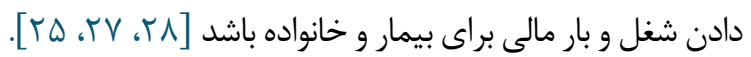

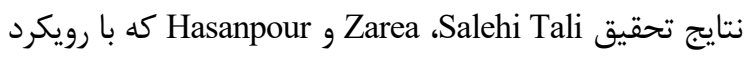
كيفى انجام شده بود نيز مؤيد اين موضوع بود كه روح و روان مراقبان خانكى بيماران تحت همودياليز بهدليل وجود مشكلات

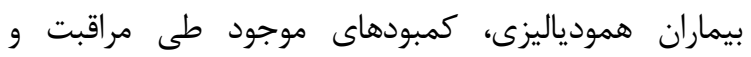

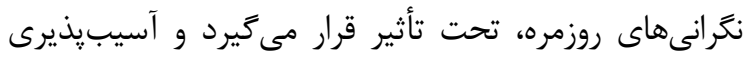

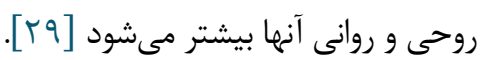

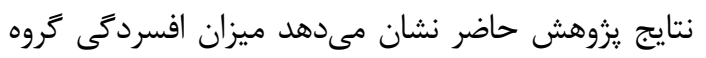

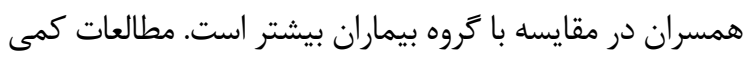

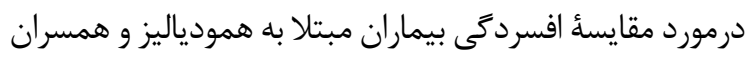

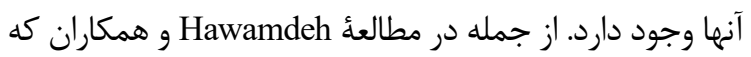

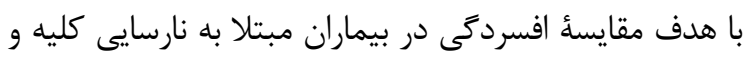

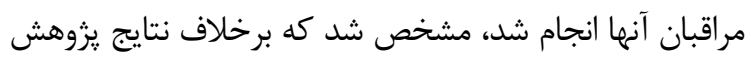
حاضر، ميزان افسردى بيماران، بيشتر از افسردگى مراقبان بوده

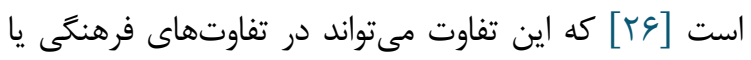
حتى تفاوت در سيستم حمايتى مراقبان ريشه داشته باشد إندا. يافتههاى تحقيق حاضر دربارئ كيفيت زندگىى، بيانكر اين

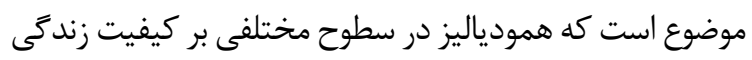

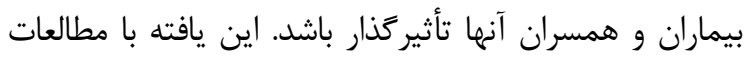
كذشته همسويى دارد كه نشان دادند كيفيت زندكى مراقبان

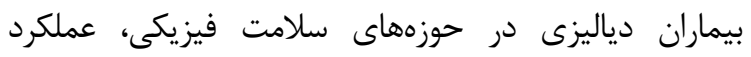

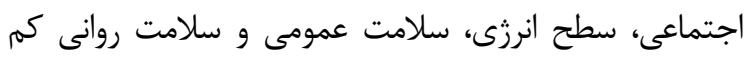

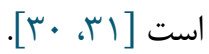

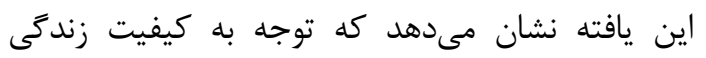

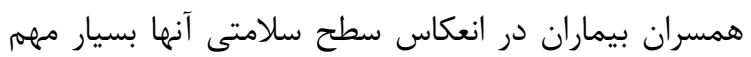

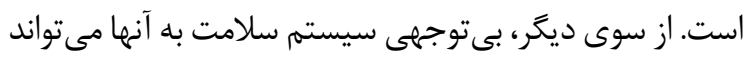

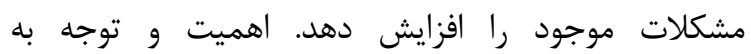
آسيب: يذيرى مراقبان تا حدى است كه محققان بيان كردهاند

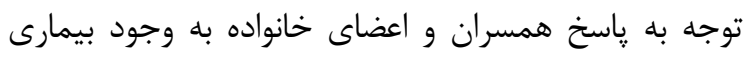

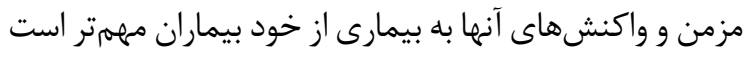

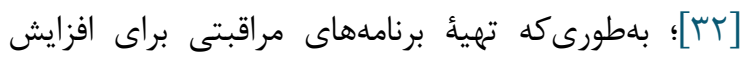

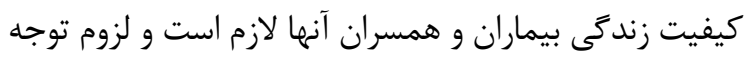
و رفع حالشهاى موجود براى اين قشر محسوس و ضرورى به نه نظر مىرسد. درك و تعمق در نكر شها، صفات و ويزَّى هاى

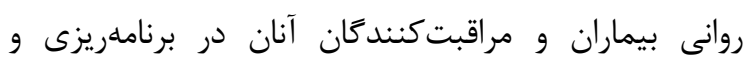

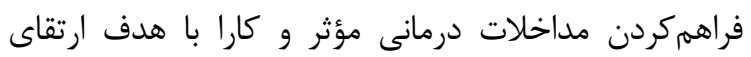
كيفيت زندگى هر دو گروه اهميت دارد [بسانس] 


$$
\text { TF أ مقايسٔ ميزان افسردگى و كيفيت زندگى بيماران تحت همودياليز و همسران آنها }
$$

$$
\text { همال تشكرداليز و همسران آنها كه در اين يثوهش شركت كردند }
$$$$
\text { بين نويسند }
$$$$
\text { منابع مالى منابع مالى اين مطالعه توسط نويسندگان تامين شده است. }
$$$$
\text { بيمار و همسر وى، مشاوره، خانوادهدرمانى، گروههاى حمايتى }
$$

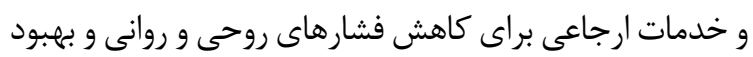$$
\text { كيفيت زندكى توجه شود. }
$$

\section{References}

1. Ye JJ, Zhou TB, Zhang YF, Wang Q, Su YY, Tang $\mathrm{JM}, \mathrm{Li}$ HY. Levels of vitamin $\mathrm{D}$ receptor and CYP24A1 in patients with end-stage renal disease. African health sciences. 2016;16(2):462-7. [DOI:10.4314/ahs.v16i2.14] [PMID] [PMCID]

2. IZADPANAH AM, HADAVI M, BAHRAMI TH. The effect of foot reflexology on severity of fatigue in haemodialysis patients.

3. Iranian Consortium of Dialysis. Calendar of Dialysis by the End of 2016. Annual data report: atlas of chronic kidney disease and end-stage renal disease in islamic repoblic of iran 1395 [Available from: http://www.icdgroup.org/Content/Upload/pdf/1395.p df. (Persian)

4. Lozano R, Naghavi M, Foreman K, Lim S, Shibuya K, Aboyans V, Abraham J, Adair T, Aggarwal R, Ahn SY, AlMazroa MA. Global and regional mortality from 235 causes of death for 20 age groups in 1990 and 2010: a systematic analysis for the Global Burden of Disease Study 2010. The lancet. 2012 Dec 15;380(9859):2095-128.

5. Zheng J, You LM, Lou TQ, Chen NC, Lai DY, Liang YY, Li YN, Gu YM, Lv SF, Zhai CQ. Development and psychometric evaluation of the Dialysis patientperceived Exercise Benefits and Barriers Scale. International journal of nursing studies. $2010 \mathrm{Feb}$ 1;47(2):166-80. [DOI:10.1016/j.ijnurstu.2009.05.023] [PMID]

6. Baghcheghi N, Ashktorab $\mathrm{T}$, Seyedfatemi N. Relationship of Coping Strategies with Quality of Life in Women Living with Husband on Hemodialysis. Avicenna Journal of Nursing and Midwifery Care. 2017 Apr 10;25(1):9-17. [DOI:10.21859/nmj-25012]

7. Koohestani HR, Baghcheghi N. The prevalence of depression among caregivers of stroke survivors and related factors in Arak. Iranian Journal of Epidemiology. 2012 Dec 15;8(3):66-72.

8. Ashktorab $\mathrm{T}$, Baghcheghi N, Seyedfatemi N, Baghestani A. Psychometric parameters of the Persian version of the BriefCOPE among wives of patients under hemodialysis. Medical journal of the Islamic Republic of Iran. 2017;31:20. [DOI:10.18869/mjiri.31.20]

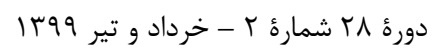

9. Mollaei F, Borhani F, Abbaszadeh A, Khabazkhoob M. Correlation between spiritual well-being and burden of care in family caregivers of cancer patients. Hayat, Journal of School of Nursing and Midwifery, Tehran Universit Mollaei F, Borhani F, Abbaszadeh A, Khabazkhoob M. Correlation between spiritual wellbeing and burden of care in family caregivers of cancer patients. Journal of hayat. 2019 Jan 10;24(4):296309.y of Medical Sciences. 2019;24(4):296-309. (Persian)

10. Adili D, Dehghani-Arani F. The relationship between caregiver's burden and patient's quality of life in women with breast cancer. Journal of Research in Psychological Health. 2018 Aug 10;10(2):30-9.

11. Calvin AO. Haemodialysis patients and end-of-life decisions: a theory of personal preservation. Journal of advanced nursing. 2004 Jun;46(5):558-66. [DOI:10.1111/j.1365-2648.2004.03030.x] [PMID]

12. Baghcheghi N, Koohestani HR. Quality of life of caregivers of elderly people with stroke at the hospitalization time and after leaving hospital, and its association with patients disabilities. Journal of Nursing and Midwifery. 2011;21(47):35-41. (Persian)

13. Shafaii M, Payami M, Amini K, Pahlevan S. The relationship between death anxiety and quality of life in hemodialysis patients. Hayat, Journal of School of Nursing and Midwifery, Tehran University of Medical Sciences. 2017;22(4):325-38. (Persian)

14. Khaki S, Khesali Z, Farajzadeh M, Dalvand S, Moslemi B, Ghanei Gheshlagh R. The relationship of depression and death anxiety to the quality of life among the elderly population. Journal of hayat. 2017 Jul 15;23(2):152-61.

15. Brodaty H, Donkin M. Family caregivers of people with dementia. Dialogues in clinical neuroscience. 2009 Jun;11(2):217.

16. Farajzadeh M, Hosseini M, Ghanei Gheshlagh R, Ghosi S, Nazari M, Nahid K. Investigating the association between Restless Leg Syndrome and depression in elderly. Iranian Journal of Rehabilitation Research. 2016 Jun 10;2(3):18-26. [DOI:10.17795/nmsjournal32585] [PMID] [PMCID]

17. Gheshlagh RG, Parizad N, Sayehmiri K. The relationship between depression and metabolic syndrome: systematic review and meta-analysis study.

$$
\text { مجله مراقبت يُرستارى و مامايى ابنسينا }
$$


Iranian Red Crescent Medical Journal. 2016 Jun;18(6). [DOI:10.5812/ircmi.26523]

18. Beck AT, Steer RA, Brown G. Manual for the Beck depression inventory-II (BDI-II).

19. Ghassemzadeh H, Mojtabai R, Karamghadiri N, Ebrahimkhani N. Psychometric properties of a Persian-language version of the Beck Depression Inventory-Second edition: BDI-II-PERSIAN. Depression and anxiety. 2005;21(4):185-92. [DOI:10.1002/da.20070] [PMID]

20. Skevington SM, Lotfy M, O'Connell K2. The World Health Organization's WHOQOL-BREF quality of life assessment: psychometric properties and results of the international field trial. A report from the WHOQOL group. Quality of life Research. 2004 Mar 1;13(2):299310. [DOI:10.1023/B:QURE.0000018486.91360.00] [PMID]

21. Nejat SA, Montazeri A, Holakouie Naieni K, Mohammad KA, Majdzadeh SR. The World Health Organization quality of Life (WHOQOL-BREF) questionnaire: Translation and validation study of the Iranian version. Journal of School of Public Health and Institute of Public Health Research. 2006 Jul 15;4(4):1-2.

22. Mashayekhi F, Pilevarzadeh M, Rafati F. The assessment of caregiver burden in caregivers of hemodialysis patients. Materia socio-medica. 2015 Oct;27(5):333. [DOI:10.5455/msm.2015.27.333-336] [PMID] [PMCID]

23. Alnazly E. Coping strategies and socio-demographic characteristics among Jordanian caregivers of patients receiving hemodialysis. Saudi Journal of Kidney Diseases and Transplantation. 2016 Jan 1;27(1):101. [DOI:10.4103/1319-2442.174088] [PMID]

24. Turkmen K, Yazici R, Solak Y, Guney I, Altintepe L, Yeksan M, Tonbul HZ. Health-related quality of life, sleep quality, and depression in peritoneal dialysis and hemodialysis patients. Hemodialysis International. 2012 Apr;16(2):198-206. [DOI:10.1111/j.15424758.2011.00648.x] [PMID]

25. Klaric D, Klaric V. Depression in end stage renal disease: comparison between patients treated with hemodialysis and peritoneal dialysis. Journal of Life Sciences. 2012 May 1;6(5).

26. Hawamdeh S, Almari AM, Almutairi AS, Dator WL. Determinants and prevalence of depression in patients with chronic renal disease, and their caregivers. International journal of nephrology and renovascular disease. 2017; 10:183 [DOI:10.2147/IJNRD.S139652] [PMID] [PMCID]

27. Eghbali M, Shahqolian N, Nazari F, Babaee S. Comparing problems of patients with chronic renal failure undergoing hemodialysis and peritoneal dialysis referring to medical university's hospitals. Iranian Journal of Nursing and Midwifery Research. 2009 Apr 20;14(1).

28. Assefa B, Duko B, Ayano G, Mihretie G. Prevalence and factors associated with depressive symptoms among patient with Chronic Kidney Disease (CKD) in Black Lion Specialized Hospital and Saint Paulo's
Hospital Millennium Medical College, Addis Ababa, Ethiopia: Cross Sectional Study. J Psychiatry. 2016;19(390):2. [DOI:10.4172/2378-5756.1000390]

29. Salehi Tali s, Zarea k, Hasanpour A. Victim of situation: experience familial caregiver with hemodialysis patient. A qualitative study. Journal of Clinical Nursing and Midwifery. 2018;7(2):158-69.

30. Shimoyama S, Hirakawa O, Yahiro K, Mizumachi T, Schreiner A, Kakuma T. Health-related quality of life and caregiver burden among peritoneal dialysis patients and their family caregivers in Japan. Peritoneal Dialysis International. 2003 Dec 1;23(Supplement 2):S200-5. [DOI:10.1177/089686080302302s42]

31. Alvarez-Ude F, Valdés C, Estébanez C, Rebollo P. Health-related quality of life of family caregivers of dialysis patients. Journal of Nephrology. 2004;17(6):841-50. [DOI:10.1016/S10983015(10)67763-7]

32. Daneker B, Kimmel PL, Ranich T, Peterson RA. Depression and marital dissatisfaction in patients with end-stage renal disease and in their spouses. American journal of kidney diseases. 2001 Oct 1;38(4):839-46. [DOI:10.1053/ajkd.2001.27704] [PMID]

33. Habibzadeh H, Mohammadpour Y, Jafarizadeh H, Kiani P, Bahrechi A, Lak KH. A survey on quality of life in hemodialysis patient care givers. The Journal of Urmia Nursing and Midwifery Faculty. 2009;7(3):128-35.

$$
\text { دورة ^r شمارة r - خرداد و تير 9qسا }
$$

مجله مراقبت يرستارى و مامايى ابنسينا 